\title{
Selective Zinc Removal from Electric Arc Furnace (EAF) Dust by Using Microwave Heating
}

\author{
Mamdouh Omran $^{1,2} \cdot$ Timo Fabritius $^{1} \cdot$ Eetu-Pekka Heikkinen ${ }^{1}$
}

Published online: 15 April 2019

(c) The Author(s) 2019

\begin{abstract}
Recycling of electric arc furnace (EAF) dust helps to avoid disposal of wastes, conserves resources, and minimizes its environmental impact. This study aimed to investigate the selective zinc removal from EAF dust by means of microwave heating oven as a heat source. The effect of microwave heating temperature on the selective zinc removal from EAF dust was studied at temperatures of $750{ }^{\circ} \mathrm{C}, 850{ }^{\circ} \mathrm{C}$, and $950{ }^{\circ} \mathrm{C}$. The mixture of EAF dust and graphite was well homogenized and compressed to pellet and heated for $20 \mathrm{~min}$ at the microwave power of $1.1 \mathrm{~kW}$. X-ray diffraction (XRD), atomic absorption spectroscopy (AAS), and scanning electron microscope-energy dispersive X-ray spectroscopy (SEM-EDS) techniques were used to characterize the residue after microwave treatment. The results indicated that the reduction and the recovery of zinc increase with the rising temperatures. The temperature of $750{ }^{\circ} \mathrm{C}$ was insufficient for the volatilization of zinc. Zinc removal of $94 \%$ was achieved after microwave heating at $950{ }^{\circ} \mathrm{C}$. The residue that remained in the crucible was composed mainly of metallic iron and calcium ferrite. These results indicated that a temperature of $950{ }^{\circ} \mathrm{C}$ is suitable for selective removal of zinc from EAF dust, which is in accordance with the thermodynamic calculations.
\end{abstract}

Keywords EAF dust $\cdot$ Zinc removal $\cdot$ Microwave heating $\cdot$ Recycling

\section{Introduction}

Electric arc furnace (EAF) dust is a byproduct waste generated by the secondary steelmaking process in an electric arc furnace and considered as a hazardous material in most industrialized countries [1, 2]. However, EAF dust contains valuable metals such as iron, zinc, and chromium in addition to variable amounts of calcium, manganese, magnesium, and silicon [3]. Zinc represents the major element of the EAF dust, and its value varies between 7 and $40 \mathrm{wt} \%$, depending on scrap used, and the ratio of galvanized scrap utilized [4-6].

The reuse of the dusts is limited due to high $\mathrm{Zn}$ contents in the dusts. The presence of zinc causes operational

The contributing editor for this article was I. Sohn.

Mamdouh Omran

mamdouh.omran@oulu.fi; mamdouh_nasr82@yahoo.com

1 Process Metallurgy Research Group, Faculty of Technology, University of Oulu, P.O. Box: 4300, Oulu, Finland

2 Minerals Technology Department, Central Metallurgical Research and Development Institute, Cairo, Egypt problems when charged to a furnace, which affects the refractory materials, and thus decreases the productivities [2].

There are two main processes for zinc removal from EAF dust: hydrometallurgical and pyrometallurgical methods. Furthermore, a combination of both methods may also be used. The prominent pyrometallurgical method for the recovery of zinc is the Waelz process. This process is based on a carbothermic reduction of zinc oxide and volatilization of metallic zinc [7]. A high zinc recovery can be obtained from this method, but the high energy consumption is its major disadvantage [7, 8]. Hydrometallurgical processes are based on the leaching of zinc using both acidic and alkaline solutions, such as sulfuric acid [9], and hydrochloric acid. The main disadvantages of the leaching methods are the low zinc recovery, and the unwanted dissolution of iron $[4,8$, $10]$.

In the recently published work, the possibility of utilizing blast furnace sludge (BFS) to remove zinc from EAF dusts by means of microwave heating has been studied [11]. The authors concluded that BFS can be applied effectively in the removal of zinc from EAF dusts owing to the excellent microwave absorption and high carbon content of the sludge. 
The present study examines the possibility of selective zinc removal from EAF dust by means of microwave heating. The application of microwaves as a heat source in material processing has become increasingly frequent over the last three decades [7, 12-14]. Compared to conventional heating, microwave heating offers several advantages such as selective heating, rapid heating, and volumetric heating $[15,16]$.

\section{Selective Zinc Separation}

One way of metal separation from a metal oxide mixture is based on the selective reduction of one or more of the metal oxides, which are relatively unstable [17]. The zinc oxide found in the EAF dust is less stable than iron oxide. The boiling point of zinc metal is $905{ }^{\circ} \mathrm{C}$, which is lower than that of iron $\left(2860^{\circ} \mathrm{C}\right)$, and consequently the zinc oxide can be reduced, vaporized, and then collected in a separate phase from the gas [17].

HSC (version 9.6.1) database was used for the thermodynamic calculations. Carbothermic reductions of iron and zinc oxides were studied by comparing the standard Gibbs free energies of the chemical reactions presented in Eqs. (1)-(5):

$$
\begin{aligned}
& 3 \mathrm{Fe}_{2} \mathrm{O}_{3}+\mathrm{C}=2 \mathrm{Fe}_{3} \mathrm{O}_{4}+\mathrm{CO}_{(\mathrm{g})} \\
& \mathrm{Fe}_{3} \mathrm{O}_{4}+\mathrm{C}=3 \mathrm{FeO}+\mathrm{CO}_{(\mathrm{g})} \\
& \mathrm{FeO}+\mathrm{C}=\mathrm{Fe}+\mathrm{CO}_{(\mathrm{g})} \\
& \mathrm{ZnO}+\mathrm{C}=\mathrm{Zn}+\mathrm{CO}_{(\mathrm{g})} \\
& \mathrm{ZnO}+\mathrm{C}=\mathrm{Zn}_{(\mathrm{g})}+\mathrm{CO}_{(\mathrm{g})} \\
& \mathrm{ZnFe}_{2} \mathrm{O}_{4}+\mathrm{C}=\mathrm{Zn}+\mathrm{CO}_{(\mathrm{g})}+\mathrm{Fe}_{2} \mathrm{O}_{3}
\end{aligned}
$$

$\mathrm{ZnFe}_{2} \mathrm{O}_{4}+\mathrm{C}=\mathrm{Zn}_{(\mathrm{g})}+\mathrm{CO}_{(\mathrm{g})}+\mathrm{Fe}_{2} \mathrm{O}_{3}$

The standard Gibbs free energies for these reactions as a function of temperature are presented in Fig. 1. Temperatures at which the standard Gibbs free energies change from positive to negative values represent minimum temperatures at which the reduction reactions are thermodynamically possible when all the reactants and products are considered to exist in their standard states (i.e., as pure compounds). This assumption is justified for carbon, metallic iron, and zinc as well as all the oxides, whereas the gas components (i.e., carbon monoxide and gaseous zinc) can be assumed to be part of a gas mixture in which their partial pressures are less than one. Hence, by using the values presented in Fig. 1, it is possible to estimate the temperatures over which each reaction of pure compounds is spontaneous. As the partial pressures of the gas components appearing as products in reactions (1) to (5) decrease, the reactions become spontaneous at even lower temperatures than the ones presented in Fig. 1.

It is seen from Fig. 1 that all the considered oxides (i.e., hematite, magnetite, wüstite, zinc oxide, and zinc ferrite) remain unreduced in the room temperature. When temperature is increased, reduction of hematite into magnetite, reduction of magnetite into wüstite, and eventually reduction of wüstite into metallic iron become spontaneous in approximately $100{ }^{\circ} \mathrm{C}, 700^{\circ} \mathrm{C}$ and $750{ }^{\circ} \mathrm{C}$, respectively. On the other hand, the reductions of zinc oxide and zinc ferrite into zinc become spontaneous at approximately $10500^{\circ} \mathrm{C}$ and $1250{ }^{\circ} \mathrm{C}$, respectively. The boiling point of zinc $\left(907^{\circ} \mathrm{C}\right)$ is also seen in the results, as zinc is reduced to gaseous form in temperatures above its boiling point as the driving forces being larger for the reactions (4b) and (5b) than for the reactions (4a) and (5a). Thus, above this temperature,
Fig. 1 Standard Gibbs free energies as a function of temperature for the chemical reactions presented in Eqs. (1) to (5) (Color figure online)

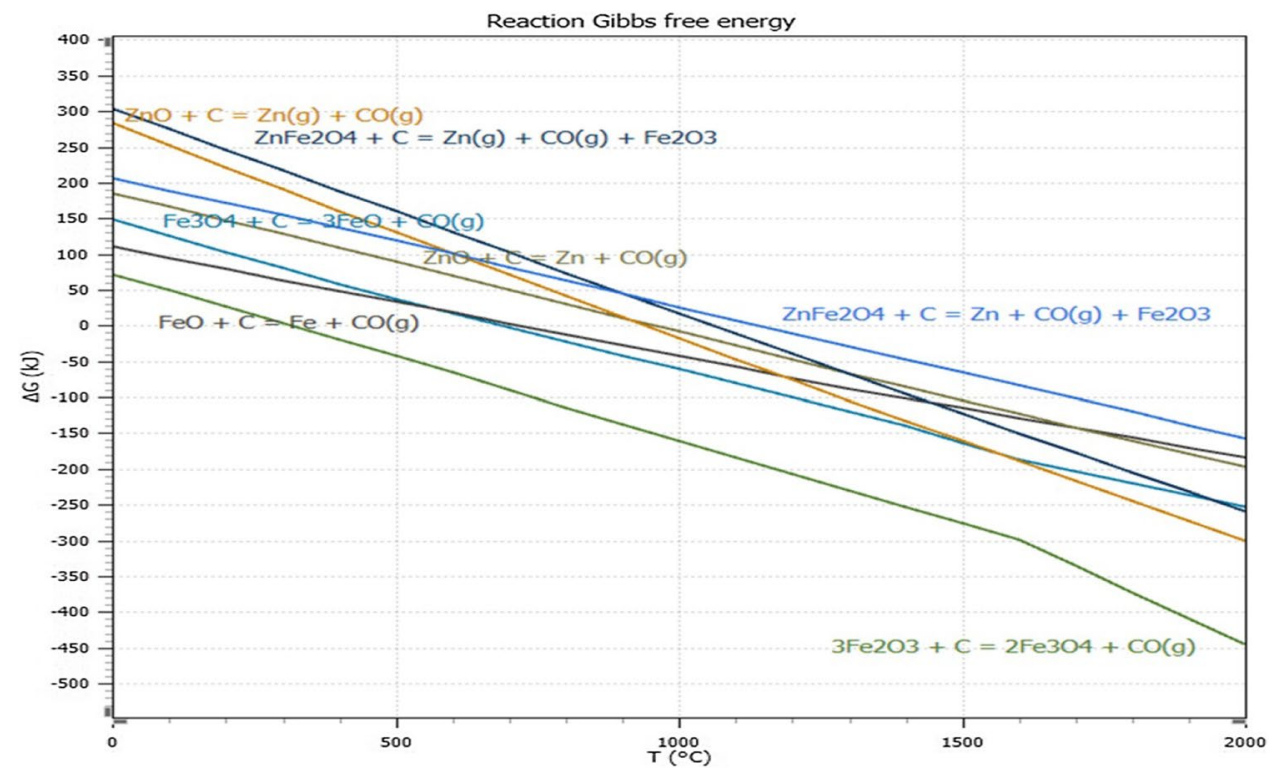


the reduced iron remains solid, whereas the reduced zinc is in gaseous form and could be separated from the gas phase by cooling.

\section{Materials and Methods}

\section{Microwave Apparatus}

The schematic diagram of the microwave apparatus is shown in Fig. 2. A single-mode microwave tube furnace with a magnetron with a frequency of $2.45 \mathrm{GHz}$ and power of $1.1 \mathrm{~kW}$ was used in the experiments.

Hundred gram sample was placed in a microwave transparent alumina crucible, which was positioned at the center of the microwave irradiation. The microwave cavity was insulated with alumina foil. At least two duplicate measurements were carried out for each sample. First, the microwave absorption abilities of raw EAF dust, EAF pellet, and graphite were measured at microwave power intensity of
$1.1 \mathrm{~kW}$. The temperature was continuously measured using a thermocouple.

The zinc removal experiments were carried out at 750 , 850 and $950{ }^{\circ} \mathrm{C}$. The temperature of the sample during microwave heating was regulated using the controls of the power supply of the magnetron. Nitrogen was used to provide an inert atmosphere with flow rate of $0.2 \mathrm{~L} \mathrm{~min}^{-1}$. A pump was used to collect the evaporated zinc from the experiments. After the experiments, the samples were allowed to cool to room temperature in the microwave oven. Chemical composition of the residue in the crucible was analyzed to determine the rate of zinc removal. The experimental flowchart is shown in Fig. 3.

\section{Pellet Preparation}

The mixture of EAF dust and graphite was well homogenized with agate and mixer. The percentage of graphite in the mixtures was calculated according to the stoichiometric amount of carbon required to reduce all the zinc oxide (as both zincite and zinc ferrite) in the sample to elemental zinc

Fig. 2 Schematic diagram of the microwave apparatus (Color figure online)
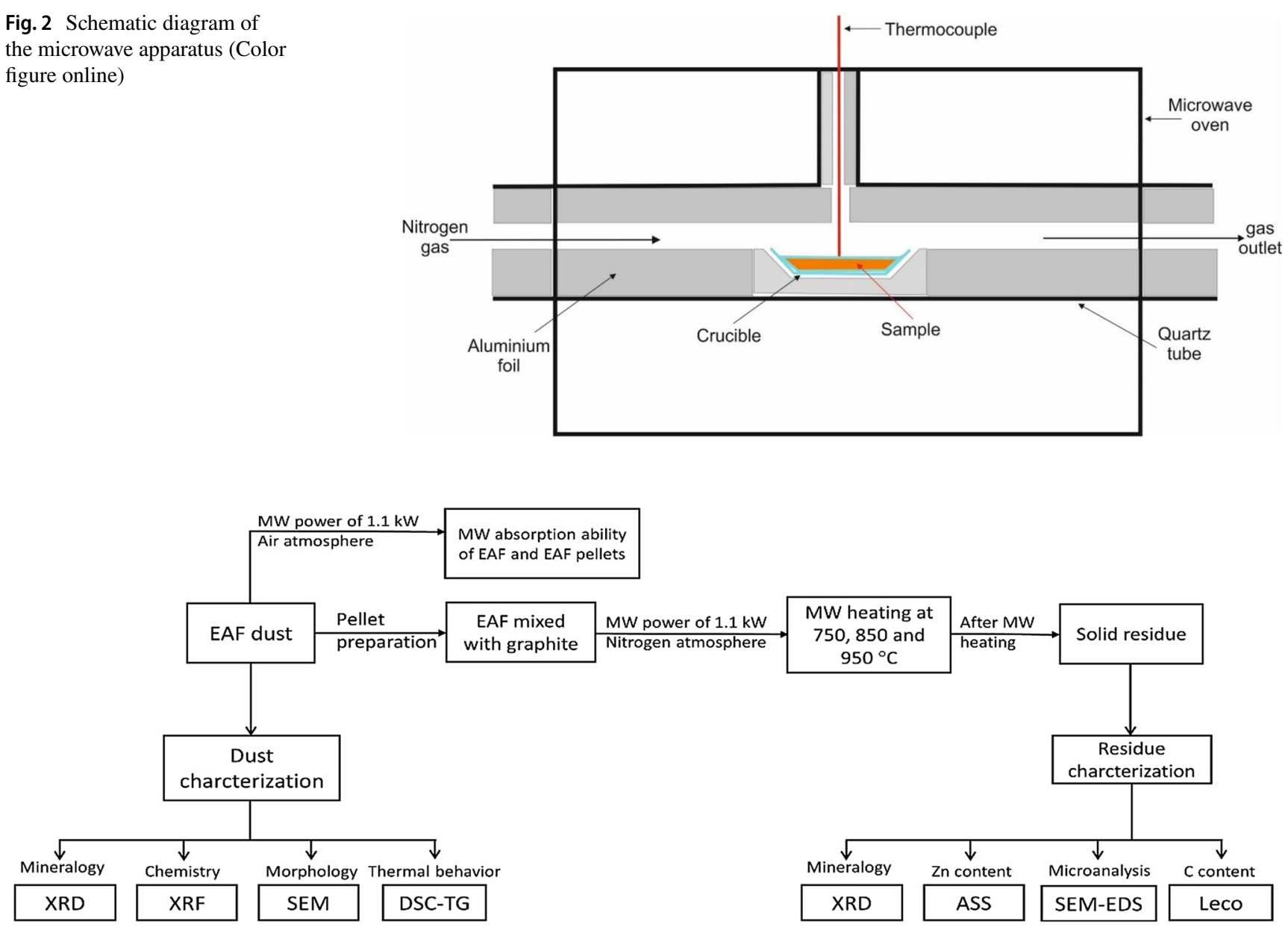

Fig. 3 Experimental flowchart 


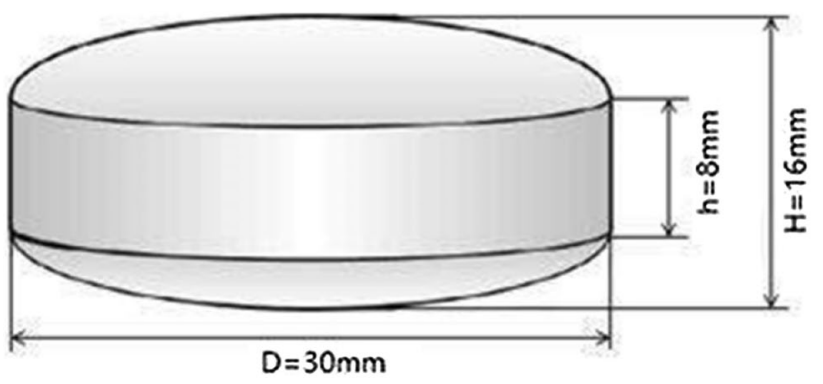

Fig. 4 Schematic of pellet dimension

and to reduce the iron oxide component of the $\mathrm{ZnFe}_{2} \mathrm{O}_{4}$ to iron metal. The ratio used in this study was 1.1 the stoichiometric amount (15 wt $\%$ graphite). A hydraulic oil press machine was used to compress the mixture at $200 \mathrm{~kg} \mathrm{f} / \mathrm{cm}^{2}$ for $1 \mathrm{~min}$. The shape and the dimensions of the pellets used in this study are shown in Fig. 4.

\section{Analytical Techniques}

The chemical composition of the EAF dust was determined using a Bruker AXS S4 Pioneer X-ray fluorescence (XRF) spectrometer. The zinc contents in the residues after the experiments were measured using atomic absorption spectroscopy (AAS). The elemental carbon content was determined using a LECO carbon analyzer. The mineralogical composition was measured using X-ray diffraction (XRD). The measurements were taken using a Rigaku diffractometer (D/Max 2200, Rigaku, Japan) with Co-Ka radiation and a nickel filter operated at a voltage of $35 \mathrm{kV}$ and anode current of $20 \mathrm{~mA}$. A field emission scanning electron microscope (FE-SEM) attached to an energy-dispersive X-ray spectroscopy (EDS) unit was used to investigate the residue after experiment. The SEM (XL30ESEM-TMP, Philips, Holland) was operated at $20 \mathrm{kV}$ in low vacuum. Differential scanning calorimetry thermogravimetry (DSC-TG) and mass spectrometry (MS) was used to study the thermal behavior of EAF dust. The test was performed using a Netzsch STA409 PC Luxx. Approximately $23.84 \mathrm{mg}$ of sample was placed in a platinum crucible on a pan of the microbalance at a heating rate of $10{ }^{\circ} \mathrm{C} \mathrm{min}{ }^{-1}$. The temperature range was $20-1400{ }^{\circ} \mathrm{C}$.

\section{Results and Discussion}

\section{EAF Dust Characterization}

The identified phases in the EAF dust are shown in Fig. 5. The iron and zinc in the dust are presented as complex oxides with spinel structure and as metal oxide. The main phases identified in the EAF dust are franklinite $\left(\mathrm{ZnFe}_{2} \mathrm{O}_{4}\right)$ and zincite $(\mathrm{ZnO})$. In addition to the main phases, portlandite $\mathrm{Ca}(\mathrm{OH})_{2}$, lime $(\mathrm{CaO})$, and periclase $(\mathrm{MgO})$ have been identified. The dust also contained minor magnetite $\left(\mathrm{Fe}_{3} \mathrm{O}_{4}\right)$, but the peaks of magnetite overlapped with the peaks of franklinite. SEM coupled with EDS was used for the identification of these phases; the results were published in a previous study [2].

The chemical composition of EAF dust sample is shown in Table 1. The major elements of the dust were $\mathrm{Zn}, \mathrm{Fe}$, $\mathrm{Ca}, \mathrm{Si}, \mathrm{Mg}$, and $\mathrm{Mn}$. The concentrations of $\mathrm{Zn}$ and $\mathrm{Fe}$ in the dust are 35.76 and $23.50 \mathrm{wt} \%$, respectively. The lime $(\mathrm{CaO})$ content is $5.93 \mathrm{wt} \%$. The carbon content is $1.5 \mathrm{wt} \%$. The concentrations of $\mathrm{Pb}, \mathrm{Cl}$, and alkaline $\mathrm{K}_{2} \mathrm{O}$ are high in the dust. The contents of $\mathrm{Pb}, \mathrm{Cl}$, and $\mathrm{K}_{2} \mathrm{O}$ are 2.15, 1.69 and $3.21 \mathrm{wt} \%$, respectively (Table 1).

SEM image showed that EAF dust is characterized by spherical form, which is forming via vaporization and condensation during cooling [2]. Franklinite and zincite
Fig. 5 X-ray diffraction pattern of EAF dust (Color figure online)

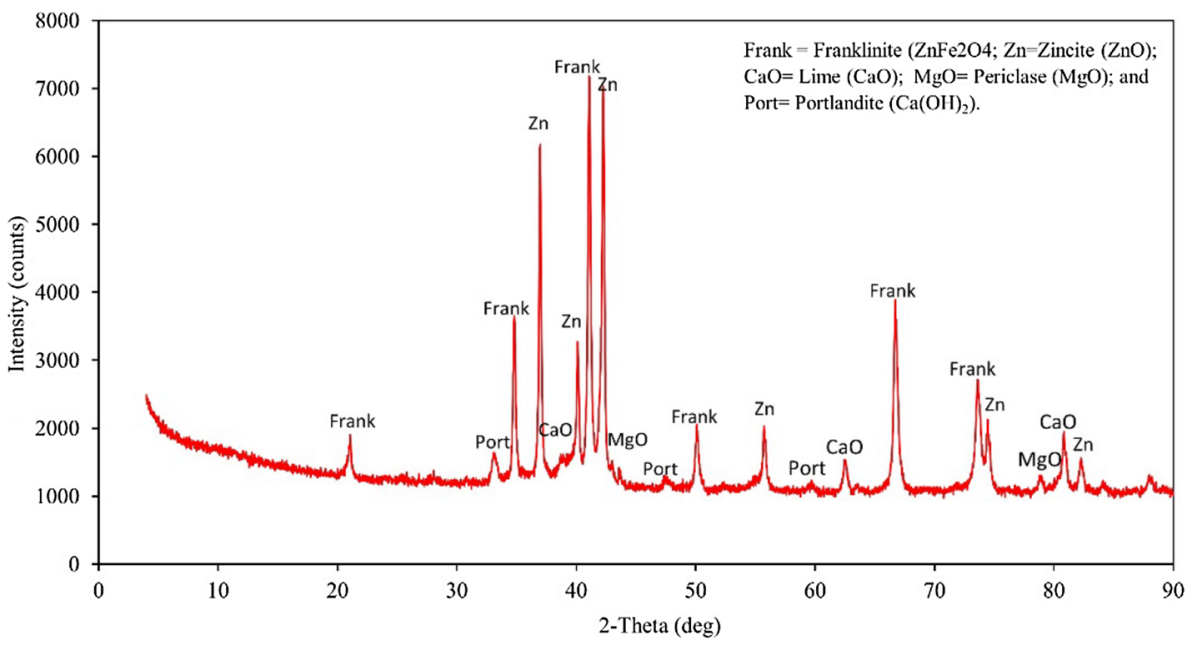


Table 1 Chemical composition of EAF dust

\begin{tabular}{lcl}
\hline Element & Concentration (wt\%) & Measuring device \\
\hline $\mathrm{C}$ & 1.5 & LECO \\
$\mathrm{Fe}$ & 23.50 & XRF \\
$\mathrm{Zn}$ & 35.76 & \\
$\mathrm{Cr}$ & 0.47 & \\
$\mathrm{CaO}$ & 5.93 & \\
$\mathrm{MgO}$ & 1.07 & \\
$\mathrm{MnO}$ & 3.99 & \\
$\mathrm{SiO}_{2}$ & 3.13 & \\
$\mathrm{~K}_{2} \mathrm{O}$ & 3.21 & \\
$\mathrm{~Pb}$ & 2.15 & \\
$\mathrm{Cl}$ & 1.69 & \\
\hline
\end{tabular}

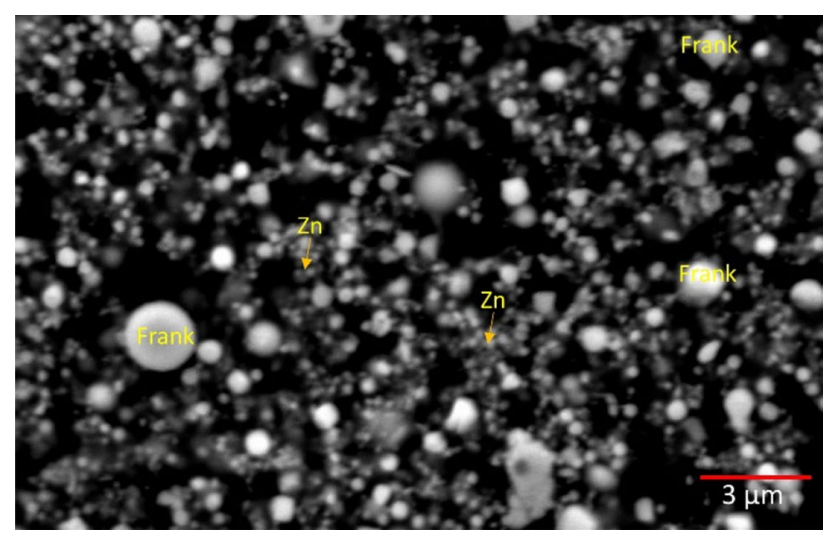

Fig. 6 SEM photomicrographs showing franklinite (Frank) and zincite $(\mathrm{Zn})$ spheres (Color figure online) spheres were identified in the EAF dust (Fig. 6). The median $\left(d_{50}\right)$ particle size for EAF dust is $1.63 \mu \mathrm{m}$.

\section{DSC-TG}

The thermal behavior of EAF dust under air atmosphere is shown in Fig. 7.

The DSC-TG curves of EAF dust exhibited two main reactions at $400-450{ }^{\circ} \mathrm{C}$ and $560-650{ }^{\circ} \mathrm{C}$ (Fig. 7). These two reactions are related to the dehydroxylation of calcium hydroxide and the decomposition of calcium carbonate, respectively $[2,18,19]$. The weak reaction occurring in the temperature range of $500{ }^{\circ} \mathrm{C}$ associated with a slight weight gain is due to the oxidation of some free iron oxide to a higher oxidation state [2]. The mass loss at the temperature above $900{ }^{\circ} \mathrm{C}$ is related to the volatilization of $\mathrm{Zn}$ and $\mathrm{Pb}[9,18]$. The carbon contained in the dust could react with zinc compounds, which evaporated into zinc vapor [2]. The reaction at the high temperature of $1260{ }^{\circ} \mathrm{C}$ was due to the formation of calcium ferrite.

\section{Microwave Heating of Raw EAF Dusts and Pellets}

The interaction of microwave with the studied materials is seen in Fig. 8 in which temperature changes of different materials are shown as a function of heating time. The heating profile shows that the temperature increased very rapidly at first after which its increase was slower. This change in the heating rates is due to the phase transformations in the materials during the microwave heating. The heating efficiency of microwaves depends on the material structure to which can
Fig. 7 TG-DSC curves for EAF dust (Color figure online)

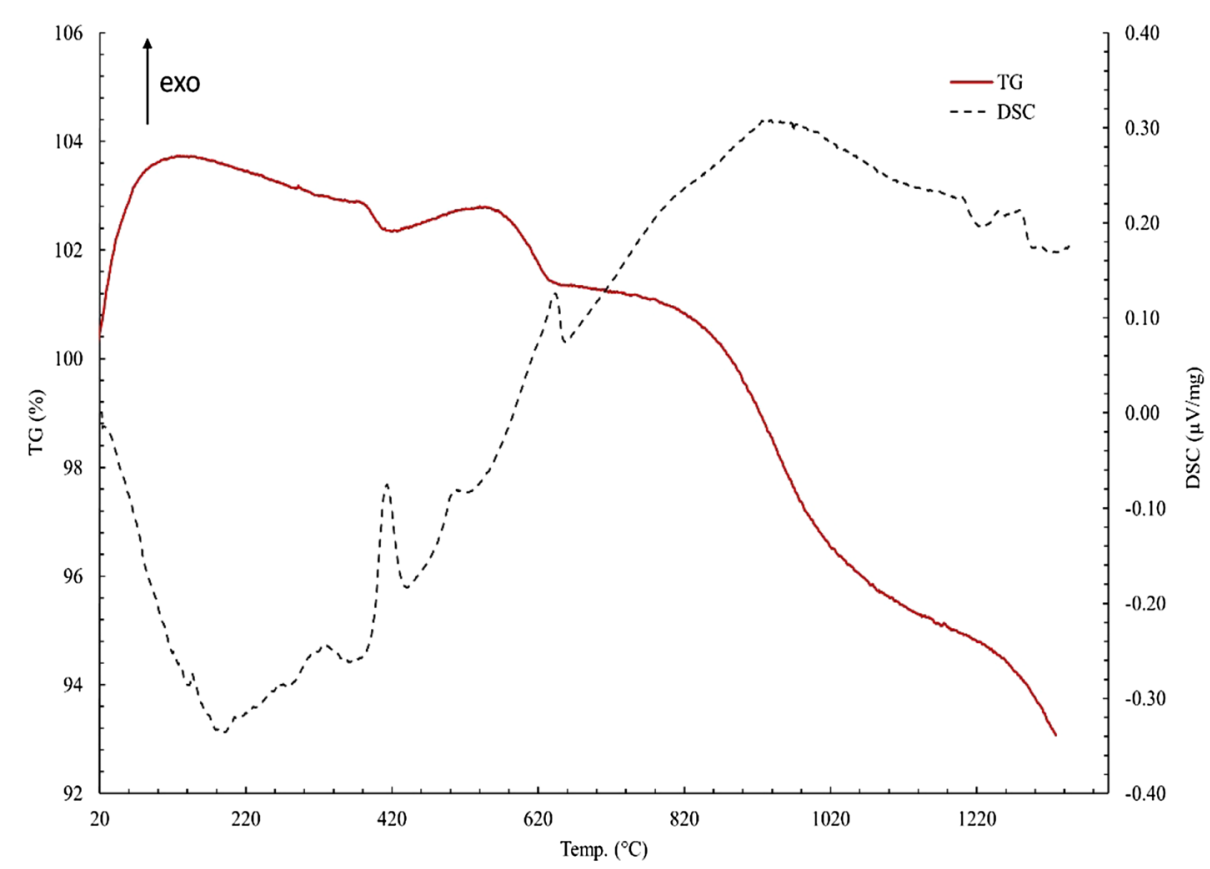


Fig. 8 Microwave heating profiles of EAF dust, EAF pellet, and graphite at $1.1 \mathrm{kw}$ microwave power (Color figure online)

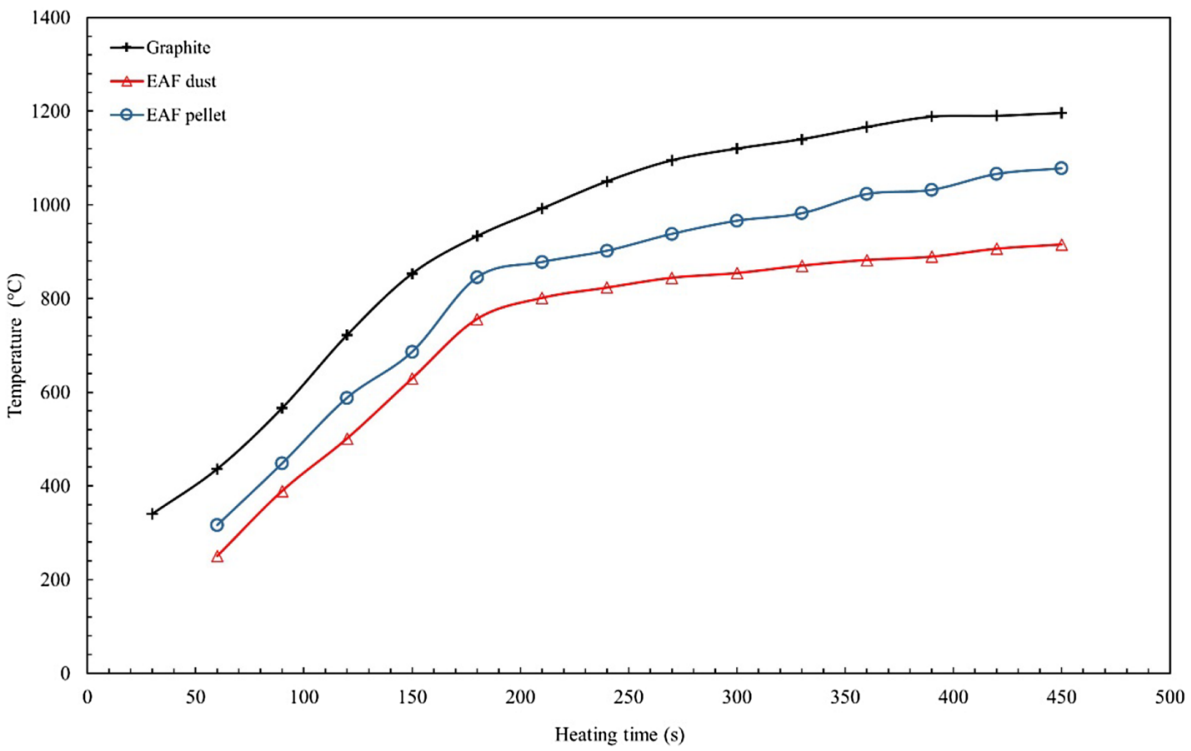

Table 2 Microwave heating properties of EAF phases [16, 22]

\begin{tabular}{ll}
\hline Phase & Microwave heating \\
\hline Franklinite $\left(\mathrm{ZnFe}_{2} \mathrm{O}_{4}\right)$ & Difficult to heat \\
Zincite $(\mathrm{ZnO})$ & Difficult to heat \\
Lime $(\mathrm{CaO})$ & Inactive \\
Periclase $(\mathrm{MgO})$ & Difficult to heat \\
Magnetite $\left(\mathrm{Fe}_{3} \mathrm{O}_{4}\right)$ & Hyperactive materials \\
Carbon & Hyperactive materials \\
\hline
\end{tabular}

be attributed the initial rapid increase in the temperature [20, 21]. The composition of the EAF dust changed during the microwave heating due to thermal decomposition of carbonates, zinc removal, and evolution of $\mathrm{CO} / \mathrm{CO}_{2}$ gases.

After microwave heating time of $180 \mathrm{~s}$, a temperature of $756^{\circ} \mathrm{C}$ was measured for the EAF dust. The good microwave heating properties of EAF dust is attributed to the contents of carbon and iron oxides, which are classified as excellent microwave absorbers [16, 22]. Table 2 gives the microwave heating properties of the mineral phases in the dust. Sun et al. [23] indicated that EAF dust is an excellent microwave absorbing material. A temperature of $907^{\circ} \mathrm{C}$ was reached when the EAF dust was heated for $5 \mathrm{~min}$ at $1.1 \mathrm{kw}$.

Graphite was used as a reducing agent in this work. The graphite is heated up rapidly (hyperactive materials), and the heating curve shows that graphite is heated easily and rapidly up to about $800{ }^{\circ} \mathrm{C}$ in less than 2 min (Fig. 8). The change in the heating rate of graphite is due to the ignition of carbon and the formation of the $\mathrm{CO} / \mathrm{CO}_{2}$ atmosphere [24].The addition of graphite to the EAF dust significantly improves the microwave heating of the dust, thus enabling the achievement of high temperatures in shorter times. For example, after $180 \mathrm{~s}$ of microwave heating, the temperature
Table 3 Chemical composition of EAF residues after microwave heating

\begin{tabular}{lccl}
\hline Element & $\begin{array}{l}\text { At } 750{ }^{\circ} \mathrm{C} \\
\text { Concentration } w t \%\end{array}$ & At $850{ }^{\circ} \mathrm{C}$ & At $950{ }^{\circ} \mathrm{C}$ \\
\hline $\mathrm{Zn}$ & 27.85 & 13.09 & 2.21 \\
$\mathrm{Fe}$ & 26.22 & 41.62 & 50.52 \\
$\mathrm{CaO}$ & 6.22 & 8.54 & 11.54 \\
$\mathrm{MgO}$ & 0.89 & 0.58 & 1.58 \\
$\mathrm{MnO}$ & 3.22 & 2.12 & 2.86 \\
$\mathrm{SiO}$ & & 4.23 & 5.23 \\
$\mathrm{~K}_{2} \mathrm{O}$ & 3.11 & 1.11 & 0.82 \\
$\mathrm{Na}$ & 2.12 & 2.04 & 1.44 \\
$\mathrm{~Pb}$ & 4.22 & - & - \\
$\mathrm{Cl}$ & 1.42 & - & - \\
$\mathrm{S}$ & 1.21 & 0.85 & 0.65 \\
$\mathrm{Re}$ & 1.18 & 3.85 & 0.58 \\
$\mathrm{Zn}$ removal \% & 6.22 & 63.39 & 93.21 \\
$\mathrm{Sum}$ & 100.21 & 99.10 & 99.81 \\
\hline
\end{tabular}

of EAF pellet increased from $756{ }^{\circ} \mathrm{C}$ to approximately $845^{\circ} \mathrm{C}$ when the EAF dust was mixed with 1.1 the stoichiometric amount of graphite.

\section{Microwave Processing of EAF Dust}

The effect of temperature on the selective zinc removal from EAF dust was studied at $750{ }^{\circ} \mathrm{C}, 850{ }^{\circ} \mathrm{C}$, and $950{ }^{\circ} \mathrm{C}$ with microwave power of $1.1 \mathrm{~kW}$ and processing time of $20 \mathrm{~min}$. The compositions and the removal grade of zinc at different temperatures are presented in Table 3. 
Fig. 9 XRD patterns of EAF residues after microwave heating for 20 min. a Raw EAF; b At $750{ }^{\circ} \mathrm{C}$; c At $850{ }^{\circ} \mathrm{C}$; d At $950{ }^{\circ} \mathrm{C}$

Fig. 10 a EAF pellet; $b$ EAF pellet after microwave treatment at $850{ }^{\circ} \mathrm{C}$ (Color figure online)
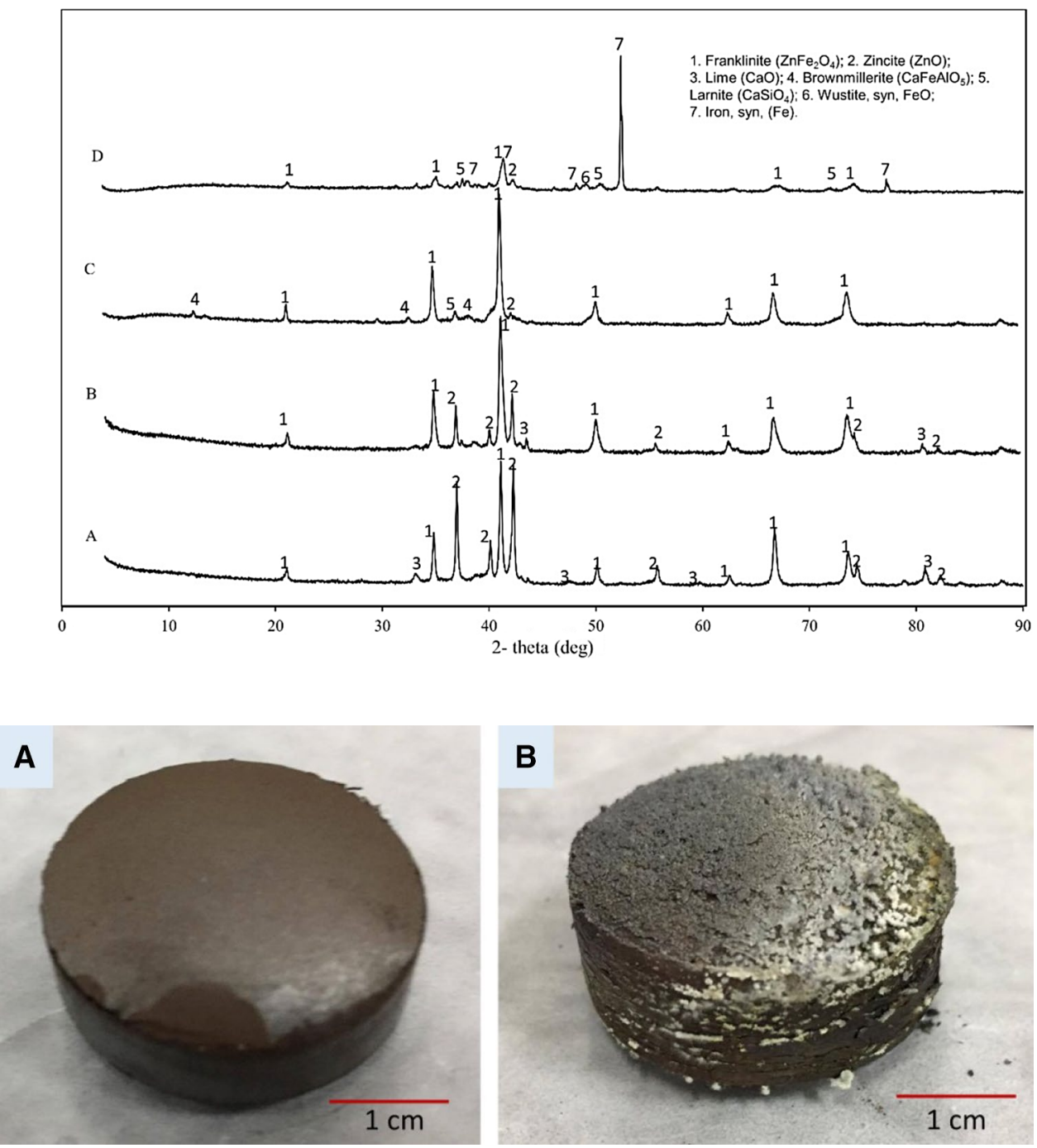

At $750{ }^{\circ} \mathrm{C}$, the chemical composition showed that the zinc content was reduced from 35.76 to $27.85 \mathrm{wt} \%(22.11 \% \mathrm{Zn}$ removal) in the residue after microwave heating for $20 \mathrm{~min}$ at $1.1 \mathrm{kw}$. The $\mathrm{Pb}$ and alkaline elements ( $\mathrm{Na}$ and $\mathrm{K}$ ) contents were reduced from $2.15,5.22$ and 3.21 to $1.42,4.22$ and $2.12 \mathrm{wt} \%$, respectively. The residual carbon content was 6.22 $\mathrm{wt} \%$. XRD indicated that the diffraction peaks of $\mathrm{ZnO}$ and $\mathrm{ZnFe}_{2} \mathrm{O}_{4}$ were still observed (Fig. 9b), whereas the peaks of $\mathrm{ZnO}$ were weakened.

At $850{ }^{\circ} \mathrm{C}$, the zinc was reduced from 35.76 to $13.09 \mathrm{wt} \%$ (63.39\% Zn removal). The lead and chloride contents were completely removed from the residue. The alkaline elements ( $\mathrm{Na}$ and $\mathrm{K}$ ) contents were reduced from 5.22 and 3.21 to 2.04 and $1.11 \mathrm{wt} \%$, respectively. The residual carbon content was $3.85 \mathrm{wt} \%$. Figure 10 in which EAF pellet is presented before and after the treatment at $850{ }^{\circ} \mathrm{C}$ shows a porous structure which indicates the evaporation of zinc from the pellet after microwave heating at $850{ }^{\circ} \mathrm{C}$. XRD showed that the peaks of $\mathrm{ZnO}$ phase disappeared after microwave heating, while the peaks of $\mathrm{ZnFe}_{2} \mathrm{O}_{4}$ were still present in the residue (Fig. 9c). The calcium ferrite and calcium silicate phases were also observed in the residues. SEM images showed that the particles were partly sintered (Fig. 11a). EDX analyses indicated that $\mathrm{Zn}$ was observed in most particles associated with calcium ferrite and calcium silicate grains (Fig. 11b, c). Calcium oxide combined with free iron oxide in the mixture to form calcium ferrite $[17,25]$.

At $950{ }^{\circ} \mathrm{C}$, the zinc content was reduced from 35.76 to $2.21 \mathrm{wt} \%$ (93.21\% $\mathrm{Zn}$ removal) in the residue after microwave heating for $20 \mathrm{~min}$ at $1.1 \mathrm{~kW}$. The $\mathrm{Na}$ and $\mathrm{K}$ contents were reduced from 5.22 and 3.21 to 1.44 and $0.88 \mathrm{wt} \%$, respectively. The volatile elements $(\mathrm{Pb}$ and $\mathrm{Cl})$ were completely removed from the residue. The peaks of $\mathrm{ZnO}$ and $\mathrm{ZnFe}_{2} \mathrm{O}_{4}$ disappeared after microwave heating (Fig. 9d). Traces of $\mathrm{ZnFe}_{2} \mathrm{O}_{4}$ were detected in the residue. The residue composed mainly of metallic iron owing to the completely reduction of zinc ferrite. SEM images showed that the residue was rich in iron and calcium ferrite grains (Fig. 12). 


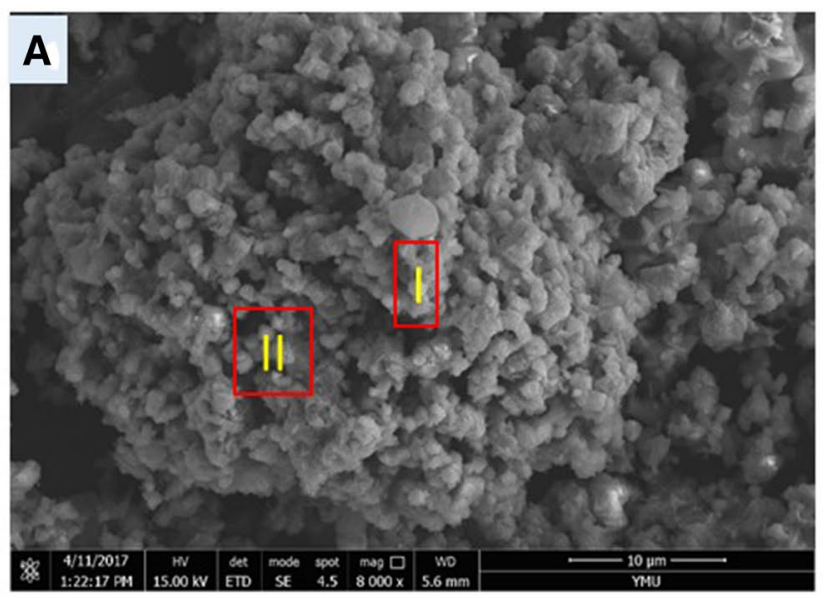

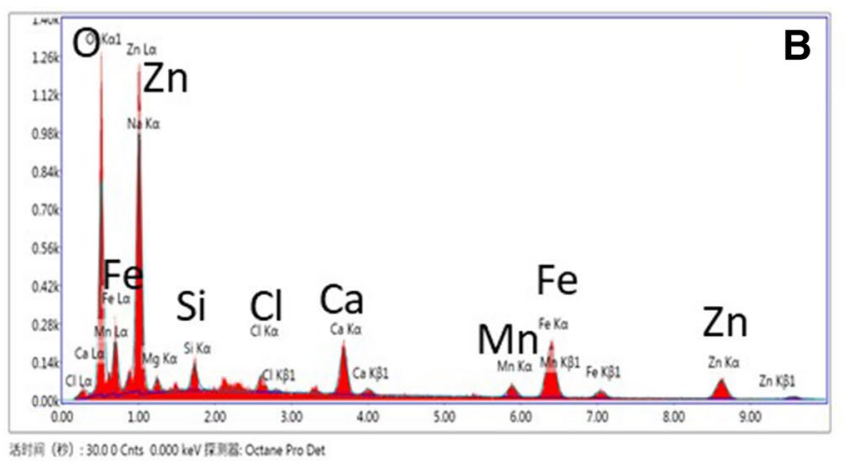

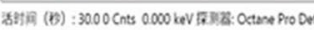

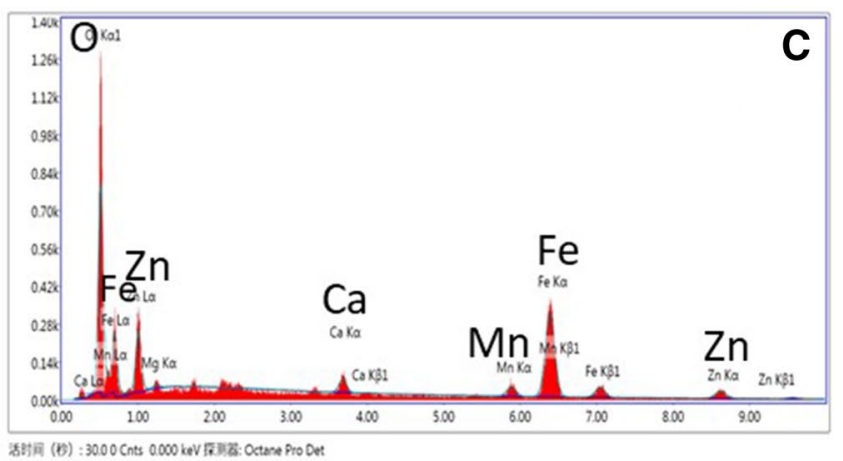

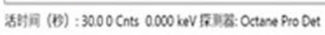

Fig. 11 a SEM image of EAF residue after microwave heating at $850^{\circ} \mathrm{C}$. b and $\mathbf{c}$ EDX analyses of (i, ii) in (a), respectively (Color figure online)

The particles were sintered during microwave heating. No zinc-bearing phases were detected in the residue with EDX.

Different grades of zinc removal were obtained at various temperatures. In general, the reduction and the recovery of zinc increase with the rising temperatures. The results indicated that the temperature of $750{ }^{\circ} \mathrm{C}$ was insufficient for the volatilization of zinc $[26,27]$. Increasing the temperature to $850{ }^{\circ} \mathrm{C}$ resulted in increased the zinc removal rate from 22.11 to $63.39 \%$. Zinc removal rate of $94 \%$ was obtained at a microwave heating temperature of $950{ }^{\circ} \mathrm{C}$. XRD revealed that after microwave heating for $20 \mathrm{~min}$ at $950{ }^{\circ} \mathrm{C}$, zinc oxide was completely volatized, and zinc ferrite was reduced to metallic iron. These results indicated that a temperature of $950{ }^{\circ} \mathrm{C}$ is capable for recovering zinc from EAF dust. This is in agreement with the values presented in the thermodynamic calculations.

Wu et al. [28] indicated that the increase of the vaporization of zinc with the increasing temperature is due to that the Boudouard equilibrium shifted to the side of $\mathrm{CO}$, which maintained the reduction effect of the gas. The other reason is the increasing driving force due to decreasing Gibbs free energy of the reduction of zinc ferrite and zinc oxide with increasing temperature. Hunt et al. [29] indicated that microwave energy is accelerated the carbothermic reduction.
They concluded that the mechanism of microwave-induced heating has effect on the thermodynamics of the Boudouard reaction, suggests that its use may yield energy savings in driving the general class of gas-carbon reactions.

Pickles et al. [17] indicated that the efficiency of zinc removal affected with the content of calcium oxide in the EAF dust. The increase in the amount of calcium oxide resulted in a significant increase in the amount of calcium ferrite, and also a corresponding decrease in the amount of iron oxide $[17,25]$. Therefore, more reducing agent was available for the $\mathrm{ZnO} / \mathrm{ZnFe}_{2} \mathrm{O}_{4}$ reduction, and this results in an improved zinc removal ratio.

Moreover, the results revealed that there were significant reductions in the contents of lead and alkaline elements after microwave heating. The chemical compositions of the residues indicated that the lead and chloride were almost vaporized and removed from EAF after microwave treatment. According to thermodynamic calculations [30], the vaporization of lead occurs with the formation of chloride since the boiling point of elemental lead is much higher than the one of zinc which can be vaporized via reduction. Owing to the lower thermodynamic stability of lead oxide in comparison with zinc oxide, high lead recoveries could be achieved at lower temperatures and reactant ratios [25, 31]. 

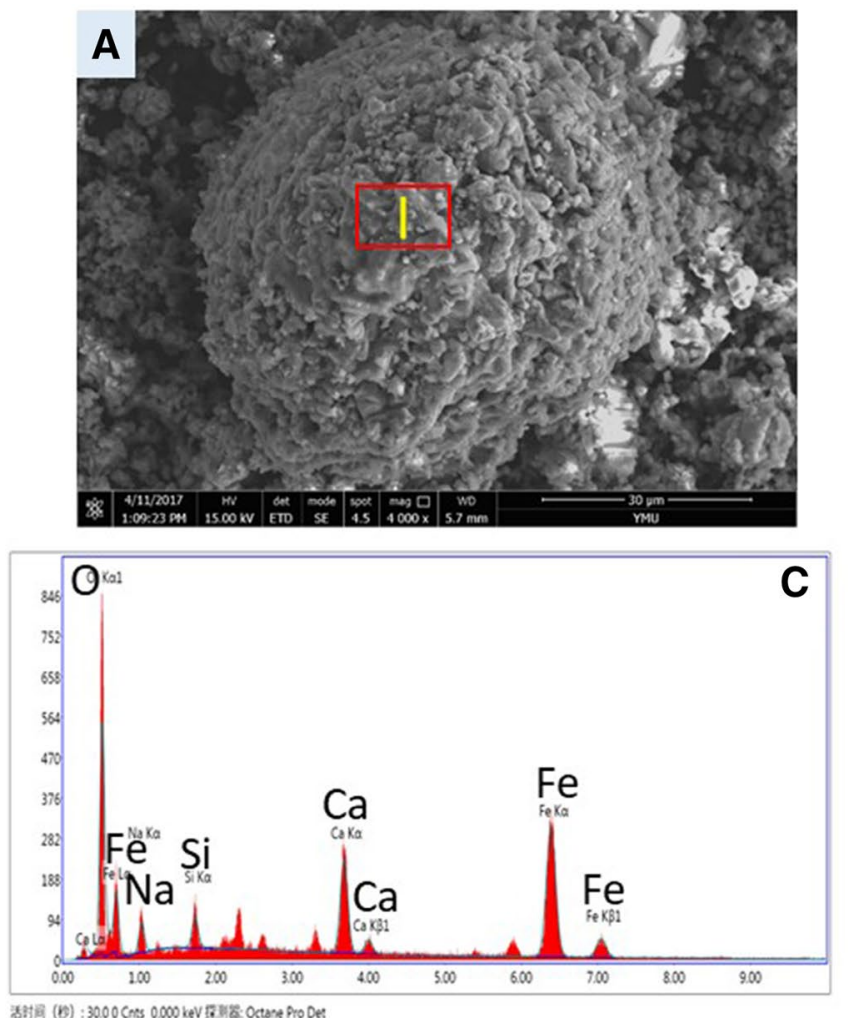
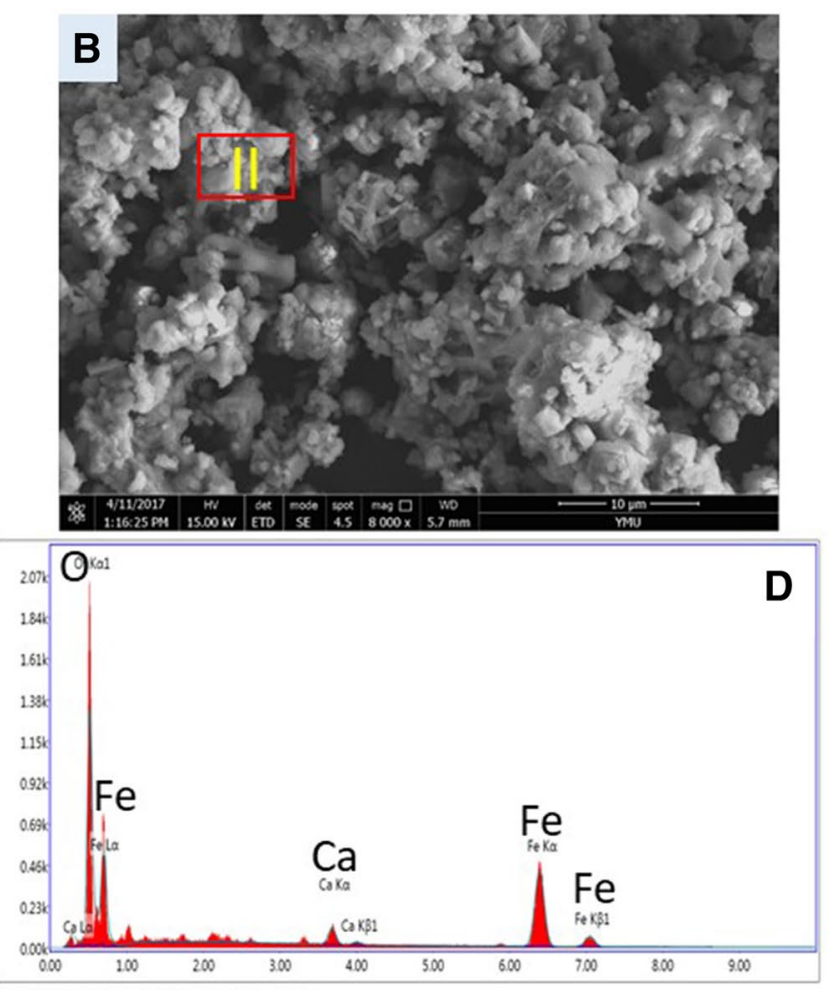

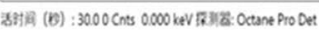

Fig. 12 a and b SEM images of EAF residues after microwave heating at 950. c and d EDX analyses of (i, ii) in (a) and (b), respectively (Color figure online)

\section{Conclusions}

The present study examined the possibility of selective zinc removal from EAF dust by means of microwave heating. The microwave heating tests indicated that EAF dusts are good microwave absorbers owing to the contents of carbon and iron oxides. The mixture of EAF dust and graphite was well homogenized, compressed to pellets, and heated in the microwave furnace for $20 \mathrm{~min}$ at $1.1 \mathrm{~kW}$ microwave power for various temperatures. The zinc removal increased with the rising temperatures. The results indicated that a temperature of $950{ }^{\circ} \mathrm{C}$ is suitable for selective removal of zinc from EAF dust, which is in accordance with the thermodynamic calculations. Thus, at this temperature, the reduced iron remains solid, whereas the reduced zinc is in gaseous form and could be separated from the gas phase by cooling. Therefore, $\mathrm{Zn}$ is recovered as a valuable element, and the remaining solid residue is reused in steelmaking processes. Moreover, the results revealed that significant reductions in the contents of lead, chloride, and alkaline elements are observed after microwave heating.

Acknowledgements Open access funding provided by University of Oulu including Oulu University Hospital. The authors gratefully acknowledge the financial support of Tekes (6905/31/2016). The authors thank Ovako Imatra for supplying the industrial sample.

\section{Compliance with Ethical Standards}

Conflict of interest On behalf of all authors, the corresponding author states that there are no conflicts of interest.

Open Access This article is distributed under the terms of the Creative Commons Attribution 4.0 International License (http://creativeco mmons.org/licenses/by/4.0/), which permits unrestricted use, distribution, and reproduction in any medium, provided you give appropriate credit to the original author(s) and the source, provide a link to the Creative Commons license, and indicate if changes were made.

\section{References}

1. Machado JGMS, Brehm FA, Moraes CAM, Dos Santos CA, Vilela ACF, Da Cunha JBM (2006) Chemical, physical, structural and morphological characterization of the electric arc furnace dust. J Hazard Mater B136:953-960

2. Omran M, Fabritius T (2017) Effect of steelmaking dust characteristics on suitable recycling process determining: ferrochrome converter (CRC) and electric arc furnace (EAF) dusts. Powder Technol 308:47-60 
3. Sofilić T, Rastovčan-Mioč A, Cerjan-Stefanović Š, NovoselRadović V, Jenko M (2004) Characterization of steel mill electricarc furnace dust. J Hazard Mater 109:59-70

4. Orhan $\mathrm{G}$ (2005) Leaching and cementation of heavy metals from electric arc furnace dust in alkaline medium. Hydrometallurgy 78:236-245

5. Salihoglu G, Pinarli V (2008) Steel foundry electric arc furnace dust management: stabilization by using lime and Portland cement. J Hazard Mater 153:1110-1116

6. Pereira CF, Galiano YL, Rodriguez-Piñero MA, Parapar JV (2007) Long and short term performance of a stabilized/solidified electric arc furnace dust. J Hazard Mater 148:701-707

7. Al-harahsheh M, Kingman S, Al-Makhadmah L, Hamilton IE (2014) Microwave treatment of electric arc furnace dust with PVC: dielectric characterization and pyrolysis-leaching. J Hazard Mater 274:87-97

8. Jha MK, Kumar V, Singh RJ (2001) Review of hydrometallurgical recovery of zinc from industrial wastes. Res Conserv Recycling 33:1-22

9. Oustadakis P, Tsakiridis PE, Katsiapi A, Agatzini-Leonardou S (2010) Hydrometallurgical process for zinc recovery from electric arc furnace dust (EAFD) Part I: characterization and leaching by diluted sulphuric acid. J Hazard Mater 179:1-7

10. Trung ZH, Kukurugya F, Takacova Z, Orac D, Laubertova M, Miskufova A, Havlik T (2011) Acidic leaching both of zinc and iron from basic oxygen furnace sludge. J Hazard Mater 192(3):1100-1107

11. Omran M, Fabritius T (2019) Utilization of blast furnace sludge for the removal of zinc from steelmaking dusts using microwave heating. Sep Purif Technol 210:867-884

12. Omran M, Fabritius T, Elmahdy A, Abdel-Khalek NA, El-Aref M, Elmanawi A (2015) XPS and FTIR spectroscopic study on microwave treated high phosphorus iron ore. App Surf Sci 345:127-140

13. Omran M, Fabritius T, Elmahdy A, Abdel-Khalek NA, Gornostayev $S$ (2015) Improvement of phosphorus removal from iron ore using combined microwave pretreatment and ultrasonic treatment. Sep Purif Technol 156:724-737

14. Nishioka K, Maeda T, Shimizu M (2002) Dezincing behaviour from iron and steelmaking dusts by microwave heating. ISIJ Int 42:S19-S22

15. Omran M, Fabritius T, Mattila R (2015) Thermally assisted liberation of high phosphorus oolitic iron ore: a comparison between microwave and conventional furnaces. Powder Technol 269:7-14

16. Haque KE (1999) Microwave energy for mineral treatment processes-a brief review. Int J Miner Process 57(1):1-24

17. Pickles CA (2008) Thermodynamic analysis of the selective carbothermic reduction of electric arc furnace dust. J Hazard Mater 150:265-278

18. Mikhail SA, Turcotte A-M (1998) Thermal reduction of steelmaking secondary materials I. Basic-oxygen-furnace dust. Thermochimica Acta 311:113-119
19. Mikhail SA, Turcotte A-M, Aota J (1996) Thermoanalytical study of EAF dust and its vitrification product. Thermochim Acta 287:71-79

20. Standish N, Huang W (1991) Microwave application in carbothermic reduction of iron ores. ISIJ Int 31(3):241-245

21. Aguilar JA, Gomez I (1997) Microwaves applied to carbothermic reduction of iron ore pellets. Int Microw Power Inst 32(2):67-73

22. Jones DA, Lelyveld TP, Mavrofidis SD, Kingman SW, Miles NJ (2002) Microwave heating applications in environmental engineering-a review. Conserv Recycl 34:75-90

23. Sun X, Hwang J, Huang X (2008) The microwave processing of electric arc furnace dust. JOM 60(10):35-39

24. Omran M, Fabritius T (2018) Improved removal of zinc from blast furnace sludge by particle size separation and microwave heating. Miner Engin 127:265-276

25. Pickles CA (2008) Thermodynamic analysis of the separation of zinc and lead from electric arc furnace dust by selective reduction with metallic iron. Sep Purif Technol 59:115-128

26. Junca E, de Oliveira JR, Restivo TAG, Espinosa DCR, Tenório JA (2016) Synthetic zinc ferrite reduction by means of mixtures containing hydrogen and carbon monoxide. J Therm Anal Calorim 123(1):631-641

27. Li M, Peng B, Chai L, Peng N, Yan H, Hou D (2012) Recovery of iron from zinc leaching residue by selective reduction roasting with carbon. J Hazard Mater 237-238:323-330

28. Wu C, Chang F, Chen W-S, Tsai M, Wang Y (2014) Reduction behavior of zinc ferrite in EAF-dust recycling with $\mathrm{CO}$ gas as a reducing agent. J Environ Manag 143:208-213

29. Hunt J, Ferrari A, Lita A, Crosswhite M, Ashley B, Stiegman A (2013) Microwave-specific enhancement of the carbon-carbon dioxide (Boudouard) reaction. J Phys Chem C 117:26871-26880

30. Heikkinen E, Makkonen H, Heino J, Heikkinen J, Seppänen M (2005) A computational study on the formation of $\mathrm{Zn}-, \mathrm{Pb}-, \mathrm{Sn}-$, $\mathrm{Cd}-$, As- and alkali compounds while recycling the integrated steel plant dusts and other iron-containing residues. International Conference on Clean Technologies in the Steel industry. 6-8. 6 . 2005. Balatonfüred, Hungary. OMBKE. pp. 112-121

31. Grabda M, Oleszek S, Shibata E, Nakamura T (2014) Study on simultaneous recycling of EAF dust and plastic waste containing TBBPA. J Hazard Mater 278:25-33

Publisher's Note Springer Nature remains neutral with regard to jurisdictional claims in published maps and institutional affiliations. 